\title{
Association of Invasive Scopulariopsis brevicaulis Infection in a Case with Systemic Lupus Erythematosus
}

\author{
Manikandan Natesan $^{1} \cdot$ Ganesh Balasubramanian ${ }^{2}$
}

Accepted: 13 May 2021 / Published online: 17 May 2021

(C) The Author(s), under exclusive licence to Springer Nature Switzerland AG 2021

To the Editor,

Scopulariopsis brevicaulis mainly causes infection in immunosuppressive host. We report a case of Scopulariopsis brevicaulis infection in a patient with systemic lupus erythematosus (SLE). A 34-year-old woman was diagnosed as having SLE 2 years ago and treated with prednisone and hydroxychloroquine. This patient had experienced joint pain, swelling, fever, butterfly rash, skin lesions, and extreme fatigue. Laboratory tests showed positive antinuclear antibodies (anti-double-stranded DNA antibody, anti-nucleosomes antibody) positive, elevated erythrocyte sedimentation rate $(92$ $\mathrm{mm} / \mathrm{h})$, C-reactive protein $(16 \mathrm{mg} / \mathrm{dl})$, and complement

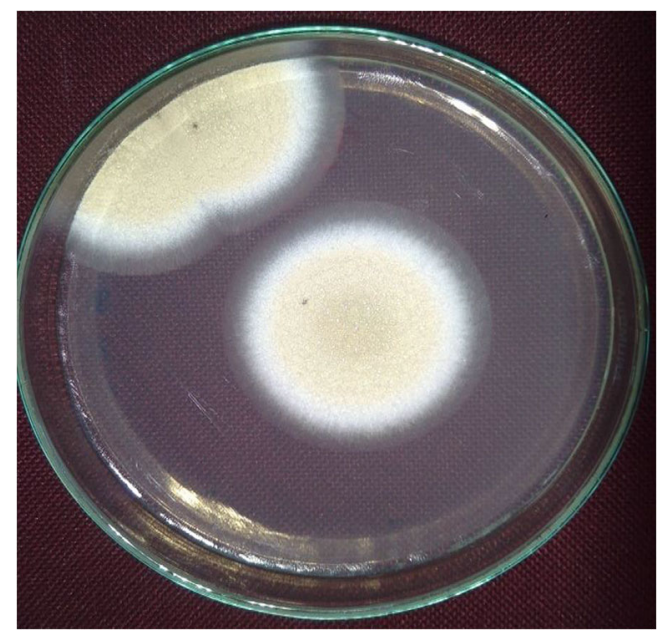

Fig. 1 SDA shows Brown colonies with powdery surface of Scopulariopsis brevicaulis

This article is part of the Topical Collection on Medicine

Manikandan Natesan

maninatesan87@gmail.com

1 Department of Microbiology and Biotechnology, Presidency College, Chennai 600005, India

2 Laboratory Division, ICMR-National Institute of Epidemiology, Chennai, India deficiency (C3: $30 \mathrm{mg} / \mathrm{dl} ; \mathrm{C} 4: 6 \mathrm{mg} / \mathrm{dl})$. Routine blood culture method showed the presence of Scopulariopsis brevicaulis. Sabouraud's dextrose agar (SDA) plate showed the brown colonies with powdery surface (Fig. 1). In addition, light microscopy observation showed the branched conidiophores with chains of lemon-shaped conidia.

\section{Discussion}

SLE is a complex autoimmune disease, encountered mainly in young females especially in their child-bearing years. Diagnosis of SLE is mainly based on the criteria of the American College of Rheumatology and SLEDAI score. SLE patients have a predisposition to develop many infections which causes morbidity and mortality. Scopulariopsis brevicaulis is a nondermatophytic mold found in soil as a saprophyte [1]. Scopulariopsis infection mainly occurs in immunosuppressive individuals and may lead to invasive fungal infection. Timely diagnosis of causative agents would be helpful to select proper treatment in SLE patients.

\section{Declarations}

Ethics and Consent Informed written consent has been obtained from patient and ethical approval was obtained.

Conflict of Interest The authors declare no competing interests.

\section{Reference}

1. Lee MH, Hwang SM, Suh MK, Ha GY, Kim H, Park JY. Onychomycosis caused by Scopulariopsis brevicaulis: report of two cases. Ann Dermatol. 2012;24(2):209-13. https://doi.org/10. 5021/ad.2012.24.2.209.

Publisher's Note Springer Nature remains neutral with regard to jurisdictional claims in published maps and institutional affiliations. 